\title{
Ibuprofen plus isosorbide dinitrate treatment in the $m d x$ mice ameliorates dystrophic heart structure
}

\author{
Clara Sciorati a,**, Lidia Staszewsky ${ }^{\mathrm{b}}$, Vanessa Zambelli $^{\mathrm{c}}$, Ilaria Russo ${ }^{\mathrm{b}}$, Monica Salio $^{\mathrm{b}}$, Deborah Novelli ${ }^{\mathrm{b}}$, \\ Giuseppe Di Grigoli ${ }^{\mathrm{d}, \mathrm{e}, \mathrm{f}}$, Rosa Maria Moresco ${ }^{\mathrm{d}, \mathrm{e}, \mathrm{f}}$, Emilio Clementi ${ }^{\mathrm{g}, \mathrm{h}, * * *}$, Roberto Latini ${ }^{\mathrm{b}, *}$ \\ a Division of Regenerative Medicine, Ospedale San Raffaele Scientific Institute, via Olgettina 58, Milan, Italy \\ b Department of Cardiovascular Research, IRCCS-Istituto di Ricerche Farmacologiche “Mario Negri”, via Giuseppe La Masa 19, 20156 Milan, Italy \\ c Department of Health Science, University of Milano-Bicocca, via Cadore 48, 20900 Monza, Italy \\ d Nuclear Medicine Department and PET Centre, San Raffaele Scientific Institute, Milan, MI, Italy \\ e IBFM-CNR, via F.lli Cervi, 93, Segrate, Milano Italy \\ ${ }^{\mathrm{f}}$ Fondazione TECNOMED, Department of Health Sciences, University of Milan-Bicocca, via Cadore 48, 20900 Monza, Italy \\ g Unit of Clinical Pharmacology, CNR Institute of Neuroscience, Department of Biomedical and Clinical Sciences, University Hospital "Luigi Sacco", Università di Milano, \\ 20157 Milan, Italy \\ h Scientific Institute, IRCCS Eugenio Medea, 23842 Bosisio Parini, Lecco, Italy
}

\section{A R T I C L E I N F O}

\section{Article history:}

Received 21 December 2012

Received in revised form 23 April 2013

Accepted 23 April 2013

\section{Keywords:}

Skeletal muscle dystrophy

Heart

Nitric oxide

Non steroidal anti-inflammatory drugs

\begin{abstract}
A B S T R A C T
Background: Co-administration of ibuprofen (IBU) and isosorbide dinitrate (ISDN) provides synergistic beneficial effects on dystrophic skeletal muscle. Whether this treatment has also cardioprotective effects in this disease was still unknown. Aims: To evaluate the effects of co-administration of IBU and ISDN (a) on left ventricular (LV) structure and function, and (b) on cardiac inflammatory response and fibrosis in $m d x$ mice. Methods: Three groups of mice were studied: $m d x$ mice treated with IBU $\left(50 \mathrm{mg} \mathrm{kg}^{-1}\right)+$ ISDN $\left(30 \mathrm{mg} \mathrm{kg}^{-1}\right)$ administered daily in the diet, $m d x$ mice that received standard diet without drugs and wild type aged-matched mice. Animals were analysed after 10-11 months of treatment. Structural and functional parameters were evaluated by echocardiography while histological analyses were performed to evaluate inflammatory response, collagen deposition, cardiomyocyte number and area. Results: Treatment for 10-11 months with IBU + ISDN preserved LV wall thickness and LV mass. Drug treatment also preserved the total number of cardiomyocytes in the LV and attenuated the increase in cardiomyocyte size, when compared to untreated $m d x$ mice. Moreover, a trend towards a decreased number of inflammatory cells, a reduced LV myocardial interstitial fibrosis and an enhanced global LV function response to stress was observed in treated $m d x$ mice. Conclusions: Treatment for 10-11 months with IBU + ISDN is effective in preventing the alterations in LV morphology of $m d x$ mice while not reaching statistical significance on LV function and cardiac inflammation.
\end{abstract}

(C) 2013 Elsevier Ltd. All rights reserved.

Abbreviations: IBU, ibuprofen; ISDN, isosorbide dinitrate; WT, wild type; DMD, Duchenne muscular dystrophy; nNOS, neuronal nitric oxide synthase; NO, nitric oxide;

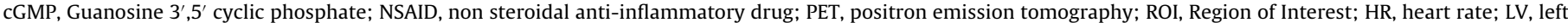

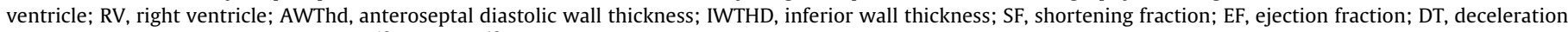
time of transmitral flow wave velocity; $\left[{ }^{18} \mathrm{~F}\right] \mathrm{FDG}, 2-\left[{ }^{18} \mathrm{~F}\right]$ fluorine-2-deoxy-D-glucose; ADME, drug absorption, distribution, metabolism, and excretion.

* Corresponding author. Tel.: +39 0239014454; fax: +39 0233200049.

** Corresponding author at: Division of Regenerative Medicine Ospedale San Raffaele, via Olgettina 58, 20132 Milan, Italy. Tel.: +39 0226436342 ; fax: +3926434786.

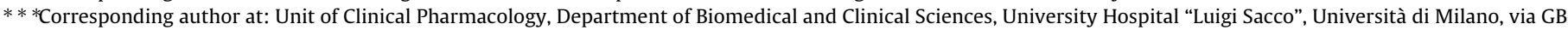
Grassi 74, 20157 Milan, Italy. Tel.: +39 0250319643; fax: +39 0250319646.

E-mail addresses: sciorati.clara@hsr.it (C. Sciorati), lidia.staszewsky@marionegri.it (L. Staszewsky), vanessa.zambelli@unimib.it(V.Zambelli), ilaria.russo@marionegri.it

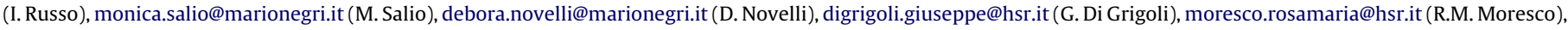
emilio.clementi@unimi.it (E.Clementi), roberto.latini@marionegri.it (R. Latini). 


\section{Introduction}

Duchenne muscular dystrophy (DMD) is a degenerative disease caused by mutations in the dystrophin encoding-gene affecting 1 of 3600-6000 live male births a year. Mutations result in muscle degeneration and necrosis leading patients to death during their mid-twenties, in most cases because of impaired respiratory function [1]. Cardiac dysfunction significantly contributes to death (10-20\%) even in those cases with a delayed disease onset [2-5].

New and promising experimental strategies have been developed for DMD treatment focused on restoring skeletal or cardiac muscle function [6-11]; effective therapies able to ameliorate function of both tissues are still poorly developed [12,13].

A commonly used model to study cardiac pathology in DMD are $m d x$ mice that lack dystrophin due to nonsense mutations: these animals, similarly to DMD patients, develop moderate myocardial fibrosis, detectable at 6-8 months of age [14] followed by cardiac dysfunction that becomes recordable by echocardiography in 11-12 months old animals [15].

The reduced functional dystrophin in cardiomyocytes leads to increase oxidative stress, alterations in cellular $\mathrm{Ca}^{2+}$ homeostasis, and reduction in generation of the cardioprotective messenger nitric oxide (NO) due to an impaired activity of the neuronal NO synthase (nNOS) [16-20]. These events contribute significantly to the onset and progression of the cardiac dysfunction. In particular, $m d x$ mice that over-express nNOS transgene revealed reduced fibrosis and recovery of some ECG parameters [16].

A therapy based on increasing the cellular levels of the NOgenerated second messenger cyclic GMP (cGMP) using inhibitors of the cGMP-hydrolysing phosphodiesterase- 5 was found to decrease susceptibility to cardiac sympathetic stress and reduce cardiac dysfunction in $m d x$ mice $[17,21]$.

NO has complex actions and not all of them mediated via cGMP generation; among these, particularly beneficial to the heart appear to be the regulation of bioenergetics and mitochondrial function controlling metabolic changes that has been shown to anticipate cardiomyopathy [22,23]. Thus a NO-based therapy is conceivably a better option to treat cardiomyopathy in DMD than a simple enhancement of cGMP levels.

An important pathogenic mechanism of cardiomyopathy in both DMD patients and animal models of dystrophy is persistent inflammation that further damages cardiomyocytes and induces fibrosis [14,24].

We recently found that the combination of a non-steroidal antiinflammatory drug (NSAID) and NO release has beneficial effects on skeletal muscle in dystrophic mice and in human patients [25-28]. We decided to investigate whether such an approach is beneficial also on the DMD-associated cardiomyopathy. We tested the combination of the NSAID ibuprofen (IBU) and the NO donor drug isosorbide dinitrate (ISDN).

We evaluated the effects of chronic co-administration of IBU and ISDN on left ventricle (LV) structure and function by echocardiography and by histological analyses. In addition, we evaluated the possibility that the pharmacological treatment affects cardiac metabolism by positron emission tomography (PET).

\section{Materials and methods}

\subsection{Animals and treatments}

All animal care and experimental procedures were in accordance to the European Community guidelines and were approved by the Institutional Ethical Committee. $4 \mathrm{cv} m d x$ mice (crossed to obtain $\mathrm{C} 57 \mathrm{Bl} / 6 \mathrm{~J}$ background) and $\mathrm{C} 57 \mathrm{Bl} / 6 \mathrm{~J}$ wild type (WT) control mice (Jackson Laboratory, Maine, USA) were housed in the pathogen-free facility at the Ospedale San Raffaele Institute. Animal groups (6-8 animals per group) were treated starting at 1 month of age with a diet (Mucedola, Milano, Italy) containing the study drugs aiming at average daily doses of $30 \mathrm{mg} \mathrm{kg}^{-1}$ day $^{-1}$ of ISDN (Alexis, Lausanne, Switzerland) and $50 \mathrm{mg} \mathrm{kg}^{-1}$ day $^{-1}$ of IBU (Sigma-Aldrich, MO, USA) or with standard diet without drugs. Diets were prepared based on the average daily food intake measured for these animals $[27,28]$. Mice and food were weighed weekly. The mice were analysed at 11-12 months of age.

All animals presented a normal physical state at rest and no adverse effects were observed as pharmacological treatment consequence. No significant differences in food intake were observed among the experimental groups.

\subsection{Echocardiography}

Transthoracic echocardiography was carried out on conscious mice 10-11 months old using a Vivid I Dimensions (GE Vingmed) echo machine equipped with a 96-element linear array transducer (i13L) and a $7.5 \mathrm{MHz}$ phased array probe for pulsed-wave and colour Doppler imaging. Parasternal short and long-axis views using two-dimensional and $\mathrm{M}$-mode echocardiography were recorded on magneto-optic disc for off-line analysis by a sonographer blind to study groups. Left atrial diameter, end-diastolic and end-systolic wall thicknesses and LV internal dimensions were measured, as recommended by the American Society of Echocardiography. Only the left ventricle was analysed. LV Fractional shortening (LVFS) was calculated from M-mode short axis view and LV mass from M-mode long-axis view. LV volumes and left ventricular ejection fraction (LVEF) were calculated by the modified simple plane Simpson's rule from the parasternal long-axis view. Aortic outflow and transmitral LV inflow velocities were measured from 5 and 4 apical chamber views, respectively, by pulsed-wave Doppler. All Doppler spectra were recorded for 5-10 cardiac cycles at a sweep speed of $100 \mathrm{~mm} / \mathrm{s}$. The colour Doppler preset was at a Nyquist limit of $0.44 \mathrm{~m} / \mathrm{s}[29,30]$. Stress echocardiography with i.v. dobutamine infusions from 0 to $40 \mathrm{ng} \mathrm{g}^{-1} \mathrm{~min}^{-1}$ was carried out in a subgroup of animals of each study group. LVEF was chosen as a marker of LV systolic function, and deceleration time normalised by heart rate (DT/HR) as a marker of diastolic function in response to stress [31,32].

\subsection{Histology and immunohistochemistry}

After echocardiography animals were sacrificed. The heart was arrested in diastole by injection of a $2.5 \mathrm{M}$ solution of $\mathrm{KCl}$, removed from the chest, blotted and weighted. The atria were trimmed and ventricles weighed. The ventricles were cut into two transversal sections, one was fixed in $10 \%$ formalin and embedded in paraffin, the other included in OCT and quickly frozen on liquid nitrogencooled isopentane.

Interstitial collagen was assessed on $10 \mu \mathrm{m}$ paraffin sections of LV stained with $0.1 \%$ Sirius red [33] and quantified at a final $200 \times$ magnification with an Axioscope microscope (Kontron-Zeiss, Germany) connected to a video camera (XC-77CE CCD Video Camera Module, Sony). The resulting image was processed on the Kontron KS300 image-analysis system (Kontron-Zeiss, Germany). The content of interstitial collagen (expressed as the fractional area of the entire cross section) was averaged on nine fields selected across the wall thickness in the septum and free wall. The nature of the Sirius red-stained collagen deposit was confirmed by examining the sections under a microscope fitted with a linear cross-polarising filter that renders collagen fibres birefrigent [34]. Collagen deposition was evaluated also by hydroxyproline assay. Hearts were homogenised in $0.5 \mathrm{ml}$ of PBS and then were hydrolysed in $6 \mathrm{~N} \mathrm{HCl}$ at $110^{\circ} \mathrm{C}$ for $12 \mathrm{~h}$. Twentyfive microliters of 
lysate were added to a solution containing $0.5 \mathrm{ml}$ of $1.4 \%$ Chloramine $\mathrm{T}$ (Sigma), $10 \% \mathrm{n}$-propanol and $0.5 \mathrm{M}$ sodium acetate. After $20 \mathrm{~min}$ at room temperature, $0.5 \mathrm{ml}$ of Erlich's solution ( $1 \mathrm{M}$ p-dimethylaminobenzaldehyde [Sigma] in 70\% n-propanol, $20 \%$ perchloric acid) was added to the sample and a $15 \mathrm{~min}$ incubation at $65^{\circ} \mathrm{C}$ performed. Absorbance was measured at $550 \mathrm{~nm}$ and the amount of hydroxyproline was determined against a standard curve.

Cardiomyocyte cross-sectional area was measured in $5 \mu \mathrm{m}$ paraffin sections, stained with AlexaFluor ${ }^{\circledR} 488$-conjugated wheat germ agglutinin (Invitrogen ${ }^{\mathrm{TM}}$ ) and counterstained with bisbenzimide for nuclei identification. Area was measured by manually tracing the fibre contour on images of at least 50 cardiomyocytes in each section.

Cardiac myocyte number was determined by a quantitative morphometric method on $5 \mu \mathrm{m}$ paraffin transversal sections stained with haematoxylin at $400 \times$ magnification. Briefly, the number of myocyte nuclear profiles and the volume fraction of myocytes (i.e., after exclusion of empty spaces, blood vessels and collage/scars) were counted in 21 fields of tissue section of transversally cut muscle cells in four representative sections from each heart. Nuclear length was obtained from 25 measurements in longitudinally oriented myocytes viewed at a magnification $1000 \times$ with an Olympus IX51 microscope equipped with a high-contrast F-VIEW II camera. The number of myocyte nuclei per unit volume of myocardium was computed from the number of nuclear profiles divided by the myocyte nuclear length. Myocyte cell volume per nucleus was calculated from the volume fraction of myocytes divided by the number of myocyte nuclei per unit volume of myocardium. The total number of myocyte nuclei in each ventricle was derived from the product of the number per unit volume and the total left ventricular volume. The latter was evaluated by dividing ventricular weight by the specific gravity of muscle tissue [35].

Infiltrating leukocytes were detected by anti-CD45 immunohistochemical staining. Cryosections $(7 \mu \mathrm{m})$ were incubated with a monoclonal rat anti-mouse CD45 antibody (clone \#30-F11; R\&D Systems, Inc.) followed by an anti rat biotinylated antibody (cod BA-4001; Vector Laboratories, USA) [36]. Peroxidase activity was visualised by diaminobenzidine and nuclei were counterstained with haematoxylin. Labelled inflammatory cells were counted at $600 \times$ under light microscope (Carl Zeiss, Axioskop, West Germany) in two representative tissue sections from each heart. CD45 ${ }^{+}$cells were counted in 80 fields of each section; the total number in each animal was calculated and normalised to tissue area, expressed as number of cells $/ \mathrm{mm}^{2}$.

\subsection{Positron emission tomography (PET)}

PET imaging was performed using a YAP-(S)-PET II small animal scanner (ISE, Pisa, Italy) (field of view: $4 \mathrm{~cm} \times 4 \mathrm{~cm} \times 4 \mathrm{~cm}$; maximum sensitivity: $19 \mathrm{cps} / \mathrm{kBq}$; spatial resolution: $1.8 \mathrm{~mm}$ ). Animals were analysed at 4, 6 and 11 months of age.

Mice, fasted over night before PET study, were injected in the tail vein with $\left[{ }^{18} \mathrm{~F}\right] \mathrm{FDG}(4.1 \pm 0.01 \mathrm{MBq}$ in $50 \mu \mathrm{l}$ of $\mathrm{NaCl} 0.9 \%)$. Sixty minutes after radiotracer injection, animals were positioned prone in the scanner bed and chest was centred in the Field Of View using a laser pointing system. Mice were scanned for $30 \mathrm{~min}$ ( 6 frames of 5 min each) and during acquisition were kept under gas anaesthesia (1.5\% isoflurane) [37].

PET data were acquired in list mode using the full axial acceptance angle of the scanner (3D mode) and all images were then reconstructed using the expectation maximisation algorithm.

Quantification analysis was performed with the Analyse 7.0 software (AnalyzeDirect Inc., Overland Park, KS, United States) using the Region of Interest (ROIs) analysis. At least 10 slices
Table 1

Body and heart weights.

\begin{tabular}{llll}
\hline & WT & Untreated & IBU + ISDN \\
\hline BW $(\mathrm{g})$ & $34.4 \pm 2.5$ & $32.3 \pm 1.1$ & $34.4 \pm 0.5$ \\
$\mathrm{LV}+\mathrm{RV}(\mathrm{mg})$ & $137.0 \pm 1.9^{*}$ & $106.5 \pm 5.4$ & $128.1 \pm 6.9^{*}$ \\
$\mathrm{LV}+\mathrm{RV} / \mathrm{BW}(\mathrm{mg})$ & $3.6 \pm 0.2$ & $3.2 \pm 0.2$ & $3.7 \pm 0.2$ \\
\hline
\end{tabular}

Variables are expressed as mean \pm SEM analysed by one-way ANOVA. BW: body weight; LV + RV: left ventricle + right ventricle, WT: wild type, untreated: $m d x$ mice without drug treatment, IBU+ISDN: $m d x$ mice treatment with drugs WT: $n=6$, untreated: $n=8$, IBU+ISDN: $n=6$

$p$ value $<0.05$ vs. $m d x$ from Dunnett's comparisons post test.

for animal were analysed. ROIs were drawn in order to sample the entire heart volume using as anatomical reference Computed Tomography image obtained in WT mice. The radiopharmaceutical distribution was calculated as mean standardised uptake value (SUVmean $=$ mean activity concentration $(\mathrm{MBq} / \mathrm{g}) /[$ injected dose (MBq)/body weight $(\mathrm{g})$ ]) by correcting for injected dose and mouse weight.

\subsection{Statistical analysis}

All data are presented as mean \pm SEM. For dobutamine experiments, data are expressed as changes of echocardiographic variables from baseline to $40 \mathrm{ng} \mathrm{g}^{-1} \mathrm{~min}^{-1}$ dobutamine infusion. Experimental groups were compared by one-way-analysis of variance (ANOVA) followed by the post hoc Dunnett's test, using $m d x$ mice as reference group. For $\mathrm{CD} 45^{+}$cells analyses the Kruskall-Wallis test and Dunn's Multiple Comparison Post hoc test were used because of the non normal distribution of the variable.

All analyses were performed with the Graph Pad, PRISM 5.0 for Windows, (GraphPad Software, Inc., San Diego, California).

\section{Results}

\subsection{IBU + ISDN treatment preserves heart anatomy and shows a trend towards ameliorating LV functional performance during stress}

No significant differences in weight gain were observed among the experimental groups. LV+RV weight was $29 \%$ lower in $m d x$ untreated mice, compared to WT age-matched mice and $21 \%$ lower when compared to $m d x$ IBU + ISDN group (Table 1); similar results were obtained after indexing ventricular weight by body weight. Results of echocardiographic evaluation at rest of conscious mice are reported in Table 2. LV anteroseptal wall was $23 \%$ thinner in $m d x$ mice compared to WT and the inferior wall thickness was reduced by $20 \%$ (although this difference did not reach statistical significance). In $m d x$ mice treated with the combination of IBU + ISDN, LV anteroseptal and inferior wall thickness were significantly increased, reaching values similar to those of WT mice. LV mass in $m d x$ group was reduced by $60 \%$ of that in WT, while drug treatment normalised it.

In the $m d x$ untreated group cardiac output and stroke volume mean values were reduced by $60 \%$ and $30 \%$, respectively, with respect to those observed in WT age-matched mice; treatment increased both values although the increment did not reach statistical significance (Table 2). Similarly, transmitral E wave deceleration time, which reflects LV diastolic function, was 35\% less in $m d x$ untreated mice compared to WT mice; this variable was not affected by the drug treatment. Heart rate, LV diameters and volumes, shortening and ejection fractions were similar in the three groups.

In a separate set of experiments, we performed a stress test with dobutamine to unmask deficits in LV function not detectable by an exam in resting conditions. In $m d x$ untreated mice, the increase 

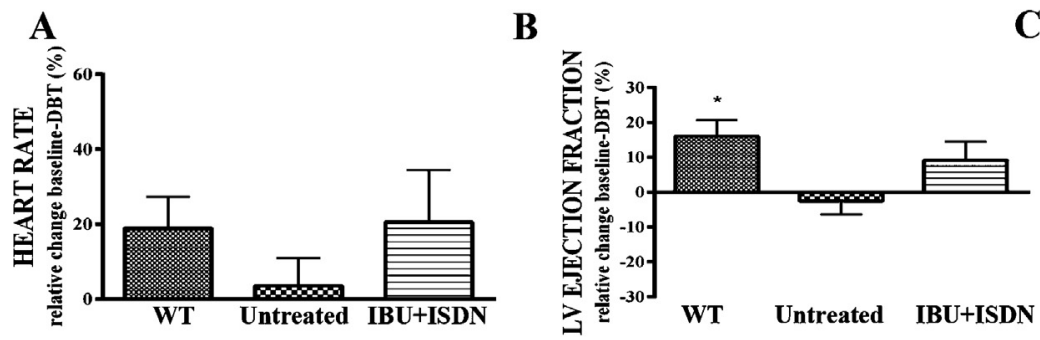

C

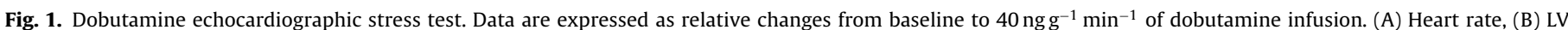

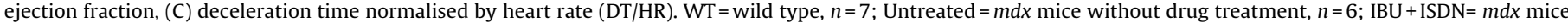
treated with the drug combination, $n=6$. Data are mean \pm SEM. ${ }^{*} p$ value $<0.05$.

in heart rate from baseline to the peak dose of $40 \mathrm{ng} \mathrm{g}^{-1} \mathrm{~min}^{-1}$ of dobutamine was less than that observed in WT mice and in mice treated with IBU + ISDN ( $4 \pm 7$ vs. $19 \pm 8 \%$ and $21 \pm 14 \%$ respectively, Fig. 1). Upon dobutamine infusion LVEF decreased in $m d x$ untreated mice while increasing significantly in WT mice $(-3 \pm 4$ vs. $16 \pm 5 \%$, Fig. 1). Similarly, deceleration time normalised by heart rate decreased in $m d x$ mice and increased in WT mice. Overall, IBU + ISDN treatment in $m d x$ mice exposed to the dobutamineinduced stress impacted positively on heart function (Fig. 1).
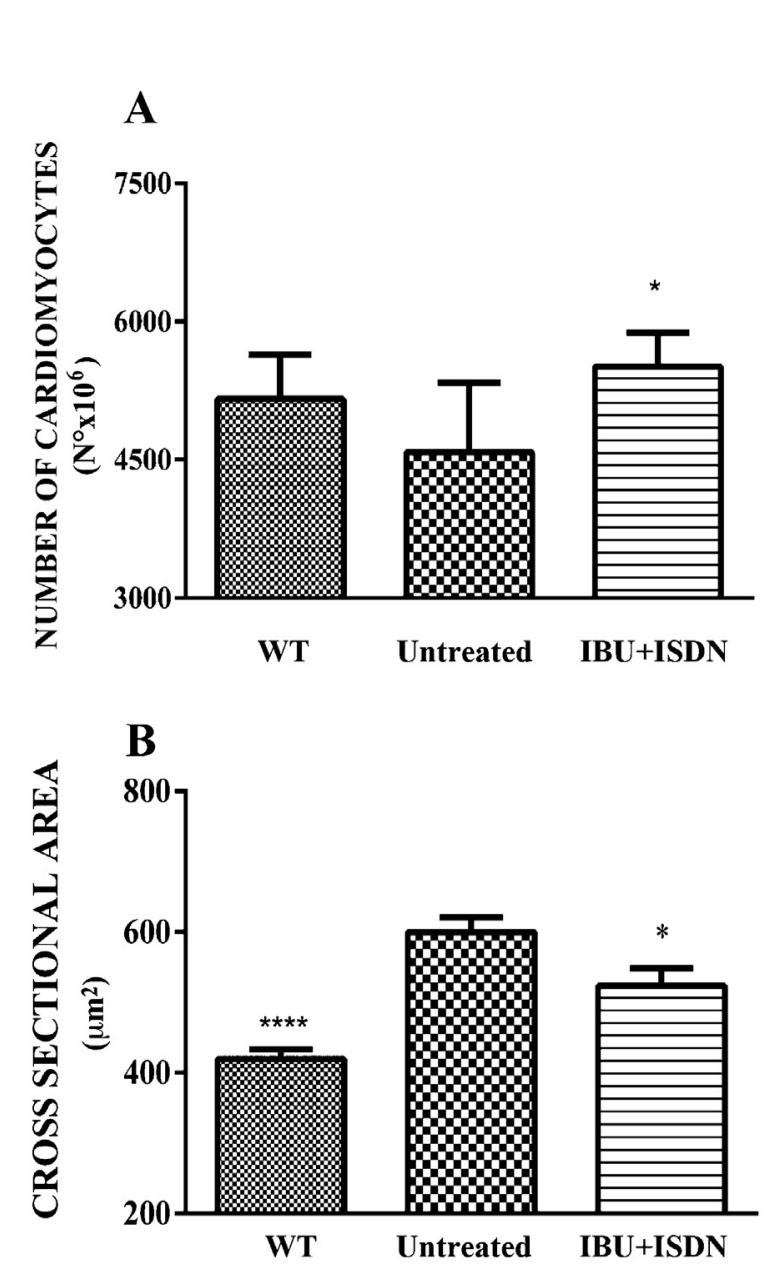

\subsection{IBU + ISDN treatment normalises the LV cardiomyocytes number and cross sectional area}

Ventricular weight was $29 \%$ lower in untreated $m d x$ compared to WT age-matched mice: treatment with IBU + ISDN attenuated the decrease in ventricular weight in agreement with data obtained for LV mass and wall thickness by echocardiography (Table 1 ). Total number of cardiomyocytes in the LV was estimated to explain the decrease in LV mass found in $m d x$ mice. Indeed, the total number
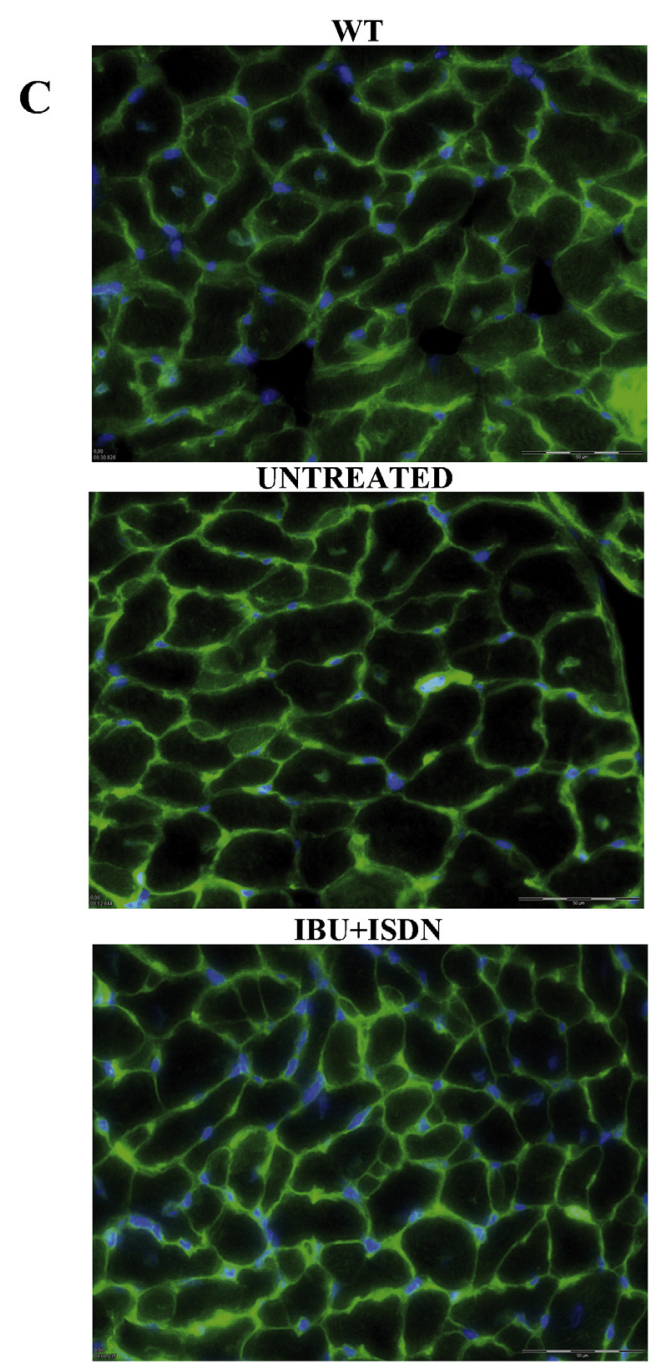

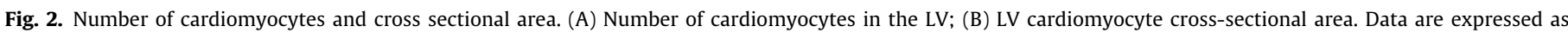

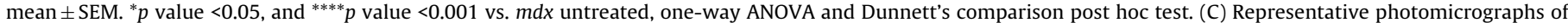

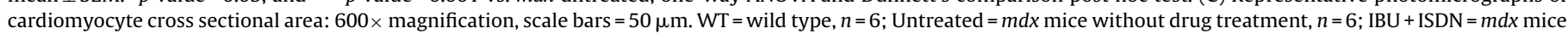
treated with the drug combination. 
B
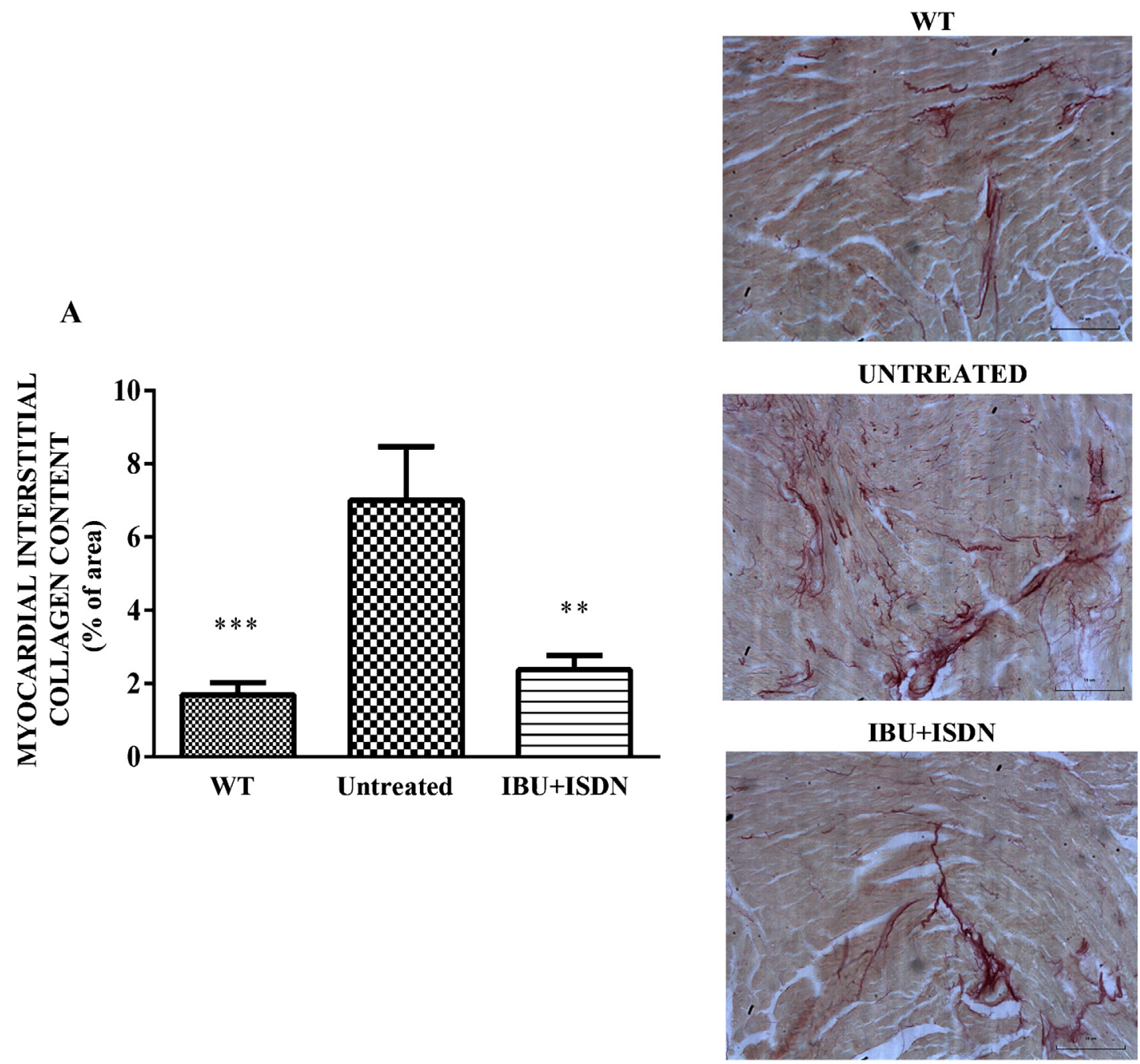

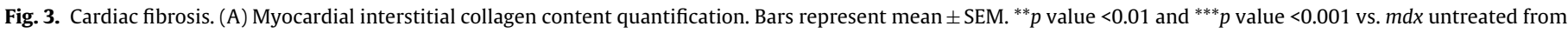

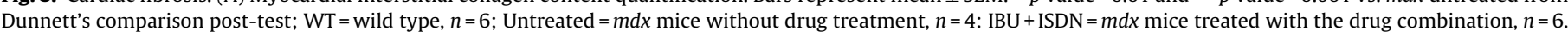

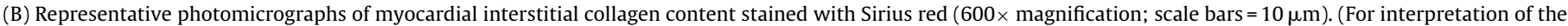
references to colour in this figure legend, the reader is referred to the web version of the article.)

of cardiomyocytes was reduced by $11 \%$ in $m d x$ untreated compared to WT age-matched mice: treatment limited significantly the loss of cardiomyocyte that were $4.6 \times 10^{6} \pm 0.3$ in $m d x$ untreated and $5.5 \times 10^{6} \pm 0.2$ in treated mice (Fig. $2 \mathrm{~A}$ ).

Cardiomyocyte cross sectional area was then measured as an index of hypertrophy: area was $43 \%$ greater in $m d x$ untreated mice compared to WT mice; the drug treatment significantly reduced cardiomyocyte enlargement by $14 \%$ (Fig. $2 \mathrm{~B}$ and representative images in C).

\subsection{IBU +ISDN treatment effects on interstitial cardiac fibrosis and tissue infiltration}

The LV of $m d x$ showed extensive focal areas of fibrosis and inflammatory infiltration. Interstitial collagen content was 5 fold higher in $m d x$ mice when compared with WT animals: treatment significantly reduced interstitial cardiac fibrosis in $m d x$ mice as shown by the Sirius red staining (Fig. 3A, and representative images in B). Measurement of hydroxyproline content showed a trend of reduction although results did not reach statistical significance (not shown).
The number of $\mathrm{CD} 45^{+}$cells in the interstitium was increased 2.5 fold in $m d x$ compared to WT mice, while it was reduced by $11 \%$ in $m d x$ mice treated with IBU + ISDN compared to untreated $m d x$ mice (Fig. 4A and representative images in B). In both dystrophic groups of mice, but not in $\mathrm{WT}, \mathrm{CD} 45^{+}$cells were present in clusters surrounding interstitial areas of fibrosis.

\subsection{IBU + ISDN treatment reduces heart glucose uptake in young mdx mice}

Metabolic changes occur in human DMD; they are considered independent determining factors for disease progression [38]. Such metabolic changes have been described in young dystrophic mice and include increased carbohydrate utilisation by heart [22].

To investigate if the drug treatment had an effect in the control of metabolic shift of dystrophic heart, we evaluated glucose uptake by PET imaging analyses after injection of $\left[{ }^{18} \mathrm{~F}\right]$ FDG. During the first 6 months of life, untreated $m d x$ mice showed a significantly higher uptake of $\left[{ }^{18} \mathrm{~F}\right] \mathrm{FDG}$ than WT mice, which was significantly reduced by treatment with IBU + ISDN (Fig. 5). No significant $\left[{ }^{18} \mathrm{~F}\right]$ FDG uptake differences were instead observed at 11 


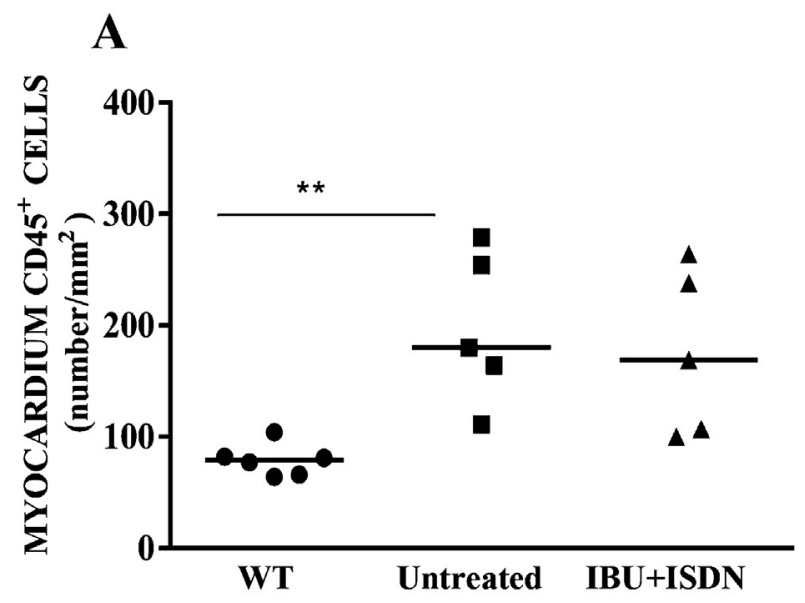

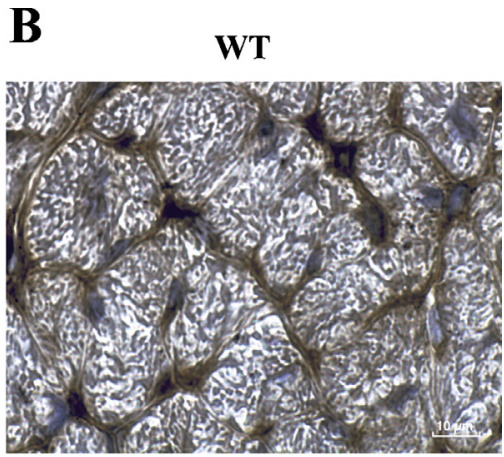

UNTREATED

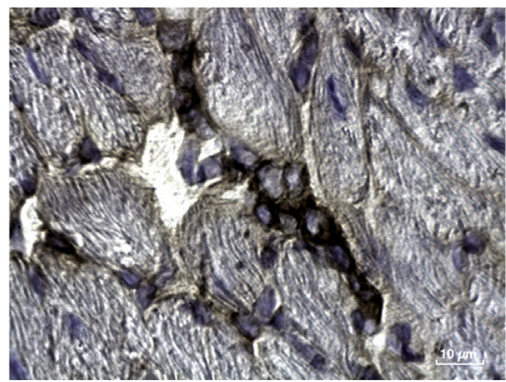

IBU+ISDN

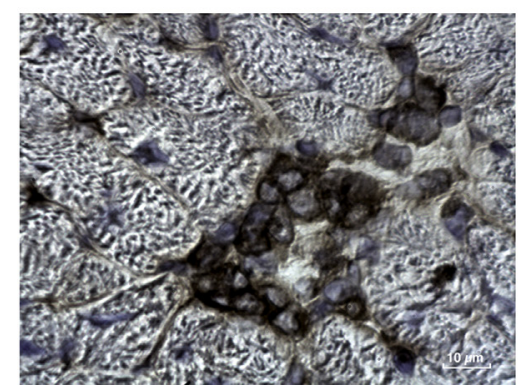

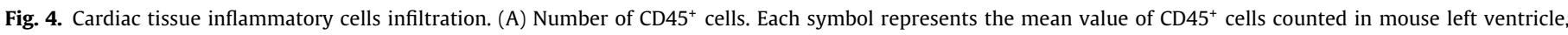

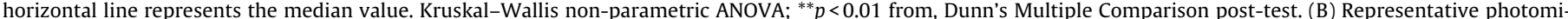

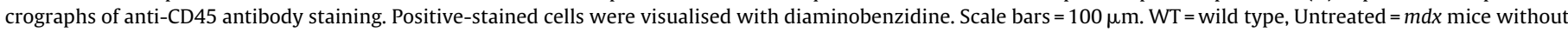
drug treatment, IBU + ISDN= $m d x$ mice treated with the drug combination.

months of age between WT, treated and untreated $m d x$ mice and at this stage the drug treatment did not affect this parameter (Fig. 5).

\section{Discussion}

DMD is a complex disease in which both skeletal and cardiac muscle damages contribute to death. While significant step forwards have been made to slow disease progression of either muscle therapies that target both tissues are still missing. Classical pharmacological approaches [6], and the novel therapies currently being tested, including the use of muscle progenitor cells [39], intravascular or direct intramuscular injection of gene therapy vectors [40], and oligonucleotide strategies for exon skipping [41] restore either the skeletal or cardiac muscle function [13,42]. This situation leads, in the clinical practice, to complex poly-therapeutic approaches. This has profound consequences in terms of drug interactions and adverse reactions.

We have recently described that a combination of the NO donor ISDN and the non steroidal anti-inflammatory drug IBU has beneficial effects on skeletal muscle structure and function that appears to have efficacy also in humans, in the absence of significant adverse drug reactions [26].
NO has several beneficial effects on heart physiology. It promotes cardiac muscle excitation contraction coupling $[43,44]$ and organic nitrates are commonly used as treatment for heart failure and stroke $[43,45,46]$. In addition, cardiomyopathy in DMD shares several aspects of skeletal muscle degeneration, including inflammation $[14,43]$. These observations prompted us to investigate the potential cardiac benefit of the therapy combining ISDN and IBU; the results we report show that this therapy preserves LV morphology and tended to ameliorate LV function response during stress.

In particular, we studied in vivo the effects of IBU + ISDN long term treatment on LV structure and function in the $m d x$ mouse model of DMD. A specific aspect of the dystrophic cardiac muscle is a reduced $L V$ wall thickness and LV mass, possibly as a consequence or dystrophin absence [47-49]. In untreated $m d x$ mice we found evidence of LV dysfunction to a degree similar to that reported by other authors that evaluated LV function $[17,50]$.

In this study we used $4 \mathrm{cv} m d x$ mice, in which alterations of LV function are less evident than in other strains as previously described $[43,44]$. We decided to use this model as it represents in our opinion a better challenge to test the efficacy of the IBU + ISDN treatment. The observed decrease in $\mathrm{CO}$ and SV may be related to diastolic dysfunction that reduce LV preload. Diastolic stiffness 
Table 2

Baseline echocardiographic parameters of conscious mice.

\begin{tabular}{lccc}
\hline & WT & Untreated & IBU + ISDN \\
\hline HR $(\mathrm{bpm})$ & $647 \pm 24$ & $614 \pm 17$ & $608 \pm 18$ \\
LVIDd $(\mathrm{mm})$ & $3.3 \pm 0.1$ & $2.9 \pm 0.1$ & $3.1 \pm 0.1$ \\
LVIDs $(\mathrm{mm})$ & $1.3 \pm 0.1$ & $1.3 \pm 0.1$ & $1.4 \pm 0.1$ \\
IVSThd $(\mathrm{mm})$ & $0.81 \pm 0.07^{* *}$ & $0.62 \pm 0.00$ & $0.87 \pm 0.03^{* * *}$ \\
AWThd $(\mathrm{mm})$ & $0.85 \pm 0.04^{*}$ & $0.69 \pm 0.04$ & $0.85 \pm 0.05^{*}$ \\
IWThd $(\mathrm{mm})$ & $0.90 \pm 0.05$ & $0.75 \pm 0.05$ & $0.93 \pm 0.03^{*}$ \\
LV mass $(\mathrm{mg})$ & $77.0 \pm 6.6^{* * *}$ & $48.6 \pm 3.5$ & $71.2 \pm 1.5^{* *}$ \\
LV mass/BW $(\mathrm{mg} / \mathrm{g})$ & $2.3 \pm 0.2^{* * * *}$ & $1.5 \pm 0.1$ & $2.1 \pm 0.03^{* *}$ \\
EDV $(\mu \mathrm{l})$ & $43 \pm 1.8^{* *}$ & $34 \pm 1.5$ & $38 \pm 1.6$ \\
EDV/BW $(\mu \mathrm{l} / \mathrm{g})$ & $1.3 \pm 0.2$ & $1.6 \pm 0.1$ & $1.1 \pm 0.1$ \\
ESV $(\mu \mathrm{l})$ & $11 \pm 2.8$ & $8 \pm 0.4$ & $9 \pm 0.9$ \\
ESV/BW $(\mu \mathrm{l} / \mathrm{g})$ & $0.33 \pm 0.1$ & $0.26 \pm 0.02$ & $0.25 \pm 0.03$ \\
EF $(\%)$ & $72 \pm 5.0$ & $75 \pm 1.3$ & $77 \pm 1.9$ \\
CO ml/min ${ }^{-1}$ & $24 \pm 1.6^{* *}$ & $15 \pm 1.3$ & $19 \pm 2.2$ \\
SV $(\mu \mathrm{l})$ & $37 \pm 2.3^{*}$ & $26 \pm 2.4$ & $30 \pm 4.7$ \\
E/A & $1.4 \pm 0.1$ & $1.3 \pm 0.1$ & $1.4 \pm 0.1$ \\
DT $(\mathrm{ms})$ & $23 \pm 1.5^{*}$ & $17 \pm 1.3$ & $18 \pm 2.3$ \\
\hline Values are mean & SEMat & & \\
\hline
\end{tabular}

Values are mean \pm SEManalyzed by one-way ANOVA. HR: heart rate, LVIDd: left ventricular diastolic diameter; LVIDs: left ventricular systolic diameter; SF: shortening fraction; IVSThd: interventricular septum diastolic thickness; AWThd: diastolic anteroseptal wall thickness; IWThd: diastolic inferior wall thickness; EDV: end diastolic volume; ESV: end systolic volume; EF: ejection fraction; CO: cardiac output; SV: stroke volume; E/A: transmitral flow E wave peak velocity; DT: deceleration time of transmitral flow E wave velocity, WT: wild type, untreated: $m d x$ mice without drug treatment, IBU + ISDN: $m d x$ mice treatment with drugs WT: $n=6$, untreated, $n=8$, IBU + ISDN: $n=6$.

${ }^{*} p$ value $<0.05$ vs. $m d x$ untreated mice from Dunnett's comparisons post test. $p$ value $<0.01$ vs. $m d x$ untreated mice from Dunnett's comparisons post test.

* $p$ value $<0.001$ vs. $m d x$ untreated mice from Dunnett's comparisons post test.

seems to be an issue of $m d x$ cardiomyopathy not related only to the content of myocardial collagen but also to a non coordinated contraction-relaxation coupling due to dystrophin deficiency [45]. In this scenario the treatment with IBU + ISDN preserved LV mass, by reducing cardiomyocyte loss. Less clear were the effects on cardiac inflammatory response, as evidenced by interstitial fibrosis and infiltrating leukocytes. In particular, the Sirius red staining indicated that the treatment reduced collagen deposition, a result not confirmed by collagen staining with hydroxyproline. The discrepancy may arise from the fact that Sirius red staining reveals interstitial collagen content, whereas hydroxyproline represents total, interstitial and perivascular, collagen content. Further studies are needed to clarify this issue.

Altered heart regulation and output in the $m d x$ mouse is associated to an impaired regulation of blood flow during exercise with ensuing low tissue perfusion and ischaemia [51]. To investigate the effect of the ISDN + IBU therapy, we used a model of dobutamineinduced cardiac stress that increases LV workload conditions. The drug treatment of the $m d x$ mice appeared to impact positively on their altered response in LV ejection fraction and deceleration time (representative of LV systolic and diastolic function, respectively), although did not reaching statistical significance. Studies in children with DMD reported that an abnormal LV function response during dobutamine stress echocardiography is a prognostic factor for subsequent clinical manifestations of heart failure [52]. A conclusive confirmation of these results regarding IBU + ISDN effect in a clinical setting has not yet been obtained, although preliminary results in patients suggest this to be the case [26].

Changes in heart metabolism occur in DMD patients and in the $m d x$ mice with increased glucose utilisation and decreased highenergy phosphate metabolism $[22,26,53]$. The importance of heart metabolism and in particular of changes in mitochondrial substrate metabolism in DMD-associated cardiac failure [54-56] has been demonstrated and corrective therapies proposed [57,58]. A recent study showed also a marked shift in substrate fuel selection from fatty acids to carbohydrates, with enhanced oxygen consumption in $m d x$ mice at 10-12 weeks of age, when no major
A

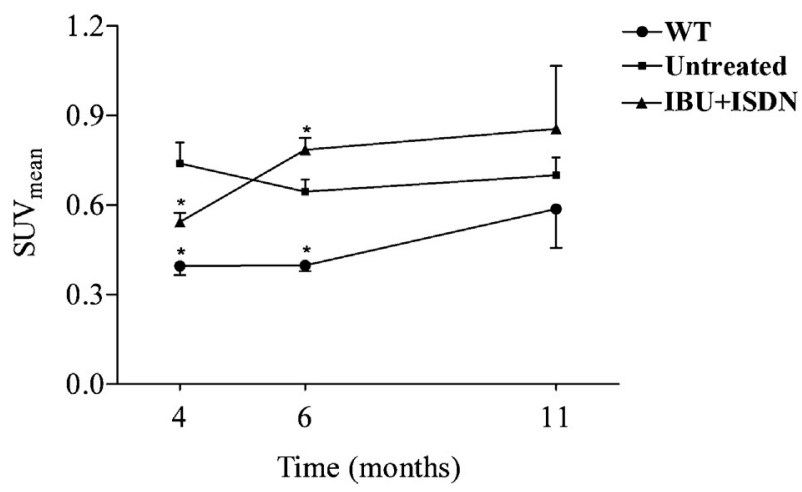

B
PET

Untreated

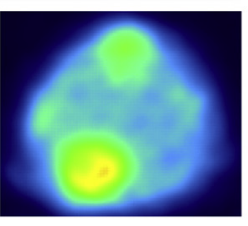

IBU+ISDN

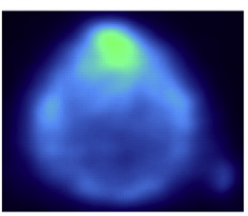

$\min$

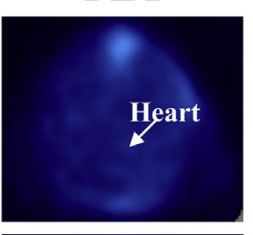

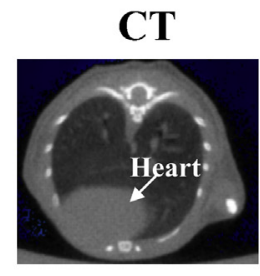

.

\section{西}

Fig. 5. Glucose uptake. (A) Quantification of $\left[{ }^{18} \mathrm{~F}\right] \mathrm{FDG}-\mathrm{PET}$ images. WT (circles $)=$ wild type, Untreated $($ squares $)=m d x$ mice without drug treatment, IBU + ISDN (triangles) $=m d x$ mice treated with the drug combination. Data are express as mean \pm s.e.m, ${ }^{*} p<0.05$ vs. $m d x$ untreated, by one-way ANOVA followed by the post hoc Dunnett's test. WT: $n=3$; untreated: $n=5$ : IBU +ISDN: $n=5$. (B) Representative transaxial $\left[{ }^{18} \mathrm{~F}\right]$ FDG-PET images of WT, Untreated $m d x$ and IBU + ISDN treated $m d x$ mice acquired at 4 months. Level of $\left[{ }^{18} \mathrm{~F}\right]$-FDG uptake is indicated by colour scale. On the right, Computed Tomography (CT) image obtained for WT mouse and used as anatomic reference.

histological or echocardiographic abnormalities are reported [22]. These findings suggest substrate metabolism shift as an (independent) factor contributing to contractile dysfunction and disease progression. We investigated the impact of the treatment on heart metabolism. We relied on [ $\left.{ }^{18} \mathrm{~F}\right]$ FDG heart uptake monitored by PET as a readout of glucose utilisation. The drug combination normalised $\left[{ }^{18} \mathrm{~F}\right]$ FDG uptake in $m d x$ mice, indicating the normalisation of heart metabolism. Such an action is one of the possible mechanisms by which the drug combination is effective.

In conclusion, we demonstrate that the combination of IBU + ISDN in mid stages of DMD positively impacted on cardiac morphology and size while the changes on cardiac function in terms of cardiac output or stroke volume and inflammation were relatively small and did not reach statistical significance. Further studies in larger animal groups are needed to confirm whether the effects we report here translate into a global amelioration of dystrophic heart function. The efficacy of the treatment on the heart, if confirmed, alongside the efficacy already reported for skeletal muscle [27] and the overall good profile of safety of these drugs suggest 
that the combination of IBU + ISDN is of therapeutic value and that it should be rapidly optimised for DMD treatment.

\section{Acknowledgements}

We wish to thank Barbara Bottazzi (Laboratory of Immunopharmacology, Istituto Clinico Humanitas) for providing anti-mouse CD45 antibody, Maria Amigoni and Margherita Scanziani (Department of Health Science, University of Milan-Bicocca) for helping in echocardiographic exams. This work was supported by the European Community's framework programme FP7/2007-2013 under grants agreements $n^{\circ} 241440$ (ENDOSTEM) and 223098 (OPTISTEM) (to EC), the Italian Ministry of Health RC 2012 (to EC), Associazione Italiana Ricerca sul Cancro (AIRC IG11362) (to EC), Parent Project Italia (to EC) and Fondazione CARIPLO "Ricerca Scientifica e Trasferimento Tecnologico, project 2009-2582” (to RL).

\section{References}

[1] Emery AE. The muscular dystrophies. Lancet 2002;359:687-95.

[2] Finstererand J, Stollberger C. The heart in human dystrophinopathies. Cardiology 2003;99:1-19.

[3] Miyoshi K. Echocardiographic evaluation of fibrous replacement in the myocardium of patients with Duchenne muscular dystrophy. British Heart Journal 1991;66:452-5.

[4] Nigro G, Comi LI, Politano L, Bain RJ. The incidence and evolution of cardiomyopathy in Duchenne muscular dystrophy. International Journal of Cardiology 1990;26:271-7.

[5] Bushby K, Muntoni F, Bourke JP.107th ENMC international workshop: the management of cardiac involvement in muscular dystrophy and myotonic dystrophy. 7th-9th June 2002, Naarden, the Netherlands. Neuromuscular Disorders 2003;13:166-72.

[6] Fairclough RJ, Perkins KJ, Davies KE. Pharmacologically targeting the primary defect and downstream pathology in Duchenne muscular dystrophy. Current Gene Therapy 2012;12:206-44.

[7] Partridge TA. Impending therapies for Duchenne muscular dystrophy. Current Opinion in Neurology 2011;24:415-22.

[8] Fairclough RJ, Bareja A, Davies KE. Progress in therapy for Duchenne muscular dystrophy. Experimental Physiology 2011;96:1101-13.

[9] Tedesco FS, Dellavalle A, Diaz-Manera J, Messina G, Cossu G. Repairing skeletal muscle: regenerative potential of skeletal muscle stem cells. Journal of Clinical Investigation 2010;120:11-9.

[10] Palmieri B, Tremblay JP, Daniele L. Past, present and future of myoblast transplantation in the treatment of Duchenne muscular dystrophy. Pediatric Transplantation 2010;14:813-9.

[11] Allen HD, Thrush PT, Hoffman TM, Flanigan KM, Mendell JR. Cardiac management in neuromuscular diseases. Physical Medicine and Rehabilitation Clinics of North America 2012;23:855-68.

[12] Malerba A, Boldrin L, Dickson G. Long-term systemic administration of unconjugated morpholino oligomers for therapeutic expression of dystrophin by exon skipping in skeletal muscle: implications for cardiac muscle integrity. Nucleic Acid Therapeutics 2011;21:293-8.

[13] Townsend D, Yasuda S, Chamberlain J, Metzger JM. Cardiac consequences to skeletal muscle-centric therapeutics for Duchenne muscular dystrophy. Trends in Cardiovascular Medicine 2009;19:50-5.

[14] Bridges LR. The association of cardiac muscle necrosis and inflammation with the degenerative and persistent myopathy of MDX mice. Journal of the Neurological Sciences 1986;72:147-57.

[15] Quinlan JG, Hahn HS, Wong BL, Lorenz JN, Wenisch AS, Levin LS. Evolution of the mdx mouse cardiomyopathy: physiological and morphological findings. Neuromuscular Disorders 2004;14:491-6.

[16] Wehling-Henricks M, Jordan MC, Roos KP, Deng B, Tidball JG. Cardiomyopathy in dystrophin-deficient hearts is prevented by expression of a neuronal nitric oxide synthase transgene in the myocardium. Human Molecular Genetics 2005; 14:1921-33.

[17] Adamo CM, Dai DF, Percival JM, Minami E, Willis MS, Patrucco E, et al. Sildenafil reverses cardiac dysfunction in the mdx mouse model of Duchenne muscular dystrophy. Proceedings of the National Academy of Sciences of the United States of America 2010;107:19079-83.

[18] Chowdharyand S, Townend JN. Role of nitric oxide in the regulation of cardiovascular autonomic control. Clinical Science (London) 1999;97:5-17.

[19] Bostick B, Yue Y, Long C, Duan D. Prevention of dystrophin-deficient cardiomyopathy in twenty-one-month-old carrier mice by mosaic dystrophin expression or complementary dystrophin/utrophin expression. Circulation Research 2008;102:121-30.

[20] Bia BL, Cassidy PJ, Young ME, Rafael JA, Leighton B, Davies KE, et al. Decreased myocardial nNOS, increased iNOS and abnormal ECGs in mouse models of Duchenne muscular dystrophy. Journal of Molecular and Cellular Cardiology 1999;31:1857-62.
[21] Khairallah M, Khairallah RJ, Young ME, Allen BG, Gillis MA, Danialou G et al. Sildenafil and cardiomyocyte-specific cGMP signaling prevent cardiomyopathic changes associated with dystrophin deficiency. Proceedings of the National Academy of Sciences of the United States of America 2008;105:7028-33.

[22] Khairallah M, Khairallah R, Young ME, Dyck JR, Petrof BJ, Des Rosiers C. Metabolic and signaling alterations in dystrophin-deficient hearts precede overt cardiomyopathy. Journal of Molecular and Cellular Cardiology 2007;43:119-29.

[23] Khairallah RJ, Khairallah M, Gelinas R, Bouchard B, Young ME, Allen BG, et al Cyclic GMP signaling in cardiomyocytes modulates fatty acid trafficking and prevents triglyceride accumulation. Journal of Molecular and Cellular Cardiology 2008;45:230-9.

[24] Wehling-Henricks M, Jordan MC, Gotoh T, Grody WW, Roos KP, Tidball JG. Arginine metabolism by macrophages promotes cardiac and muscle fibrosis in $\mathrm{mdx}$ muscular dystrophy. PLoS ONE 2010;5:e10763.

[25] Brunelli S, Sciorati C, D’Antona G, Innocenzi A, Covarello D, Galvez BG, et al Nitric oxide release combined with nonsteroidal antiinflammatory activity prevents muscular dystrophy pathology and enhances stem cell therapy. Proceedings of the National Academy of Sciences of the United States of America 2007;104:264-9.

[26] D’Angelo MG, Gandossini S, Martinelli Boneschi F, Sciorati C, Bonato S, Brighina E, et al. Nitric oxide donor and non steroidal anti inflammatory drugs as a therapy for muscular dystrophies: evidence from a safety study with pilot efficacy measures in adult dystrophic patients. Pharmacological Research 2012;65:472-9.

[27] Sciorati C, Buono R, Azzoni E, Casati S, Ciuffreda P, D’Angelo G, et al. Coadministration of ibuprofen and nitric oxide is an effective experimental therapy for muscular dystrophy, with immediate applicability to humans. British Journal of Pharmacology 2010;160:1550-60.

[28] Sciorati C, Miglietta D, Buono R, Pisa V, Cattaneo D, Azzoni E, et al. A dual acting compound releasing nitric oxide (NO) and ibuprofen, NCX 320, shows significant therapeutic effects in a mouse model of muscular dystrophy. Pharmacological Research 2011;64:210-7.

[29] Lang RM, Bierig M, Devereux RB, Flachskampf FA, Foster E, Pellikka PA, et al. Recommendations for chamber quantification. European Journal of Echocardiography 2006;7:79-108.

[30] Schiller NB, Shah PM, Crawford M, DeMaria A, Devereux R, Feigenbaum H, et al Recommendations for quantitation of the left ventricle by two-dimensional echocardiography. American Society of Echocardiography Committee on Standards, Subcommittee on Quantitation of Two-Dimensional Echocardiograms. Journal of the American Society of Echocardiography 1989;2: 358-67.

[31] Fiordaliso F, Chimenti S, Staszewsky L, Bai A, Carlo E, Cuccovillo I, et al. A nonerythropoietic derivative of erythropoietin protects the myocardium from ischemia-reperfusion injury. Proceedings of the National Academy of Sciences of the United States of America 2005;102:2046-51.

[32] Burger AJ, Notarianni MP, Aronson D. Safety and efficacy of an accelerated dobutamine stress echocardiography protocol in the evaluation of coronary artery disease. American Journal of Cardiology 2000;86:825-9.

[33] Junqueira LC, Bignolas G, Brentani RR. Picrosirius staining plus polarization microscopy, a specific method for collagen detection in tissue sections. Histochemical Journal 1979;11:447-55.

[34] Zoja C, Cattaneo S, Fiordaliso F, Lionetti V, Zambelli V, Salio M, et al. Distinct cardiac and renal effects of ETA receptor antagonist and ACE inhibitor in experimental type 2 diabetes. American Journal of Physiology Renal Physiology 2011;301:F1114-23.

[35] Anversa P, Beghi C, Kikkawa Y, Olivetti G. Myocardial response to infarction in the rat. Morphometric measurement of infarct size and myocyte cellular hypertrophy. American Journal of Pathology 1985;118:484-92.

[36] Simon DI, Dhen Z, Seifert P, Edelman ER, Ballantyne CM, Rogers C. Decreased neointimal formation in Mac-1(-/-) mice reveals a role for inflammation in vascular repair after angioplasty. Journal of Clinical Investigation 2000;105:293-300.

[37] Zambelli V, Di Grigoli G, Scanziani M, Valtorta S, Amigoni M, Belloli S, et al. Time course of metabolic activity and cellular infiltration in a murine model of acid-induced lung injury. Intensive Care Medicine 2012;38:694-701.

[38] Perloff JK, Henze E, Schelbert HR. Alterations in regional myocardial metabolism, perfusion, and wall motion in Duchenne muscular dystrophy studied by radionuclide imaging. Circulation 1984;69:33-42.

[39] Sampaolesi M, Blot S, D’Antona G, Granger N, Tonlorenzi R, Innocenzi A, et al Mesoangioblast stem cells ameliorate muscle function in dystrophic dogs. Nature 2006;444:574-9.

[40] Gregorevic P, Blankinship MJ, Allen JM, Crawford RW, Meuse L, Miller DG, et al Systemic delivery of genes to striated muscles using adeno-associated viral vectors. Nature Medicine 2004;10:828-34.

[41] Wilton S. PTC124, nonsense mutations and Duchenne muscular dystrophy. Neuromuscular Disorders 2007;17:719-20.

[42] Townsend D, Yasuda S, Li S, Chamberlain JS, Metzger JM. Emergent dilated cardiomyopathy caused by targeted repair of dystrophic skeletal muscle. Molecular Therapy 2008;16:832-5.

[43] Roeand ND, Ren J. Nitric oxide synthase uncoupling: a therapeutic target in cardiovascular diseases. Vascular Pharmacology 2012;57:168-72.

[44] Lim G, Venetucci L, Eisner DA, Casadei B. Does nitric oxide modulate cardiac ryanodine receptor function? Implications for excitation-contraction coupling. Cardiovascular Research 2008;77:256-64. 
[45] Taylor AL. Nitric oxide modulation as a therapeutic strategy in heart failure. Heart Failure Clinics 2012;8:255-72.

[46] Kapil V, Webb AJ, Ahluwalia A. Inorganic nitrate and the cardiovascular system. Heart 2010;96:1703-9.

[47] Gilroy J, Cahalan JL, Berman R, Newman M. Cardiac and pulmonary complications in Duchenne's progressive muscular dystrophy. Circulation 1963;27:484-93.

[48] Sanyal SK, Johnson WW, Thapar MK, Pitner SE. An ultrastructural basis for electrocardiographic alterations associated with Duchenne's progressive muscular dystrophy. Circulation 1978;57:1122-9.

[49] Cheng YJ, Lang D, Caruthers SD, Efimov IR, Chen J, Wickline SA. Focal but reversible diastolic sheet dysfunction reflects regional calcium mishandling in dystrophic $m d x$ mouse hearts. American Journal of Physiology Heart and Circulatory Physiology 2012;303:H559-68.

[50] Jearawiriyapaisarn N, Moulton HM, Sazani P, Kole R, Willis MS. Long-term improvement in mdx cardiomyopathy after therapy with peptide-conjugated morpholino oligomers. Cardiovascular Research 2009;85:444-53.

[51] Bredt DS. NO skeletal muscle derived relaxing factor in Duchenne muscular dystrophy. Proceedings of the National Academy of Sciences of the United States of America 1998;95:14592-3.

[52] Bosser G, Lucron H, Lethor JP, Burger G, Beltramo F, Marie PY, et al. Evidence of early impairments in both right and left ventricular inotropic reserves in children with Duchenne's muscular dystrophy. American Journal of Cardiology 2004;93:724-7.

[53] Burelle Y, Khairallah M, Ascah A, Allen BG, Deschepper CF, Petrof BJ, et al. Alterations in mitochondrial function as a harbinger of cardiomyopathy: lessons from the dystrophic heart. Journal of Molecular and Cellular Cardiology 2009;48:310-21.

[54] Ingwall JS. Energy metabolism in heart failure and remodelling. Cardiovascular Research 2009;81:412-9.

[55] Ashrafianand H, Frenneaux MP. Metabolic modulation in heart failure: the coming of age. Cardiovascular Drugs and Therapy 2007;21:5-7.

[56] Zhang W, ten Hove M, Schneider JE, Stuckey DJ, Sebag-Montefiore L, Bia BL, et al. Abnormal cardiac morphology, function and energy metabolism in the dystrophic mdx mouse: an MRI and MRS study. Journal of Molecular and Cellular Cardiology 2008;45:754-60.

[57] Ascah A, Khairallah M, Daussin F, Bourcier-Lucas C, Godin R, Allen BG, et al. Stress-induced opening of the permeability transition pore in the dystrophindeficient heart is attenuated by acute treatment with sildenafil. American Journal of Physiology Heart and Circulatory Physiology 2010;300. H144-153.

[58] Buyse GM, Van der Mieren G, Erb M, D’Hooge J, Herijgers P, Verbeken E, et al. Long-term blinded placebo-controlled study of SNT-MC17/idebenone in the dystrophin deficient mdx mouse: cardiac protection and improved exercise performance. European Heart Journal 2009;30:116-24. 